16

\title{
Наносекундное воздействие интенсивного лазерного излучения на тонкие плёнки TiAIN
}

\author{
(ㄷ Г.Д. Ивлев ${ }^{1}$, В.А. Зайков ${ }^{1}$, И.М. Климович ${ }^{1}$, Ф.Ф. Комаров ${ }^{2}$, О.Р. Людчик ${ }^{1}$ \\ ${ }^{1}$ Белорусский государственный университет, \\ 220030 Минск, Беларусь \\ ${ }^{2}$ Институт прикладных фризических проблем им. А.Н. Севченко \\ Белорусского государственного университета, \\ 220045 Минск, Беларусь \\ e-mail: ivlev_gennadii@mail.ru
}

Поступила в редакцию 20.08. 2019 г.

В окончательной редакции 20.08.2019 г.

Принята к публикации 09.09.2019 г.

\begin{abstract}
Измерены спектральные зависимости $(\lambda=0.35-1.0 \mu \mathrm{m})$ коэффициентов пропускания и отражательной способности $R$ тонких плёнок бинарного нитрида TiAIN, осаждённых методом магнетронного распыления мишени на стеклянные подложки и на пластины $\mathrm{Si}$. Плёнки TiAlN/Si толщиной $0.5 \mu \mathrm{m}$ подвергались воздействию одиночных наносекундных $(70 \mathrm{~ns})$ импульсов излучения рубинового лазера с целью исследования влияния лазерно-индуцированных в TiAlN теплофизических процессов на динамику $R(t)$ на длинах волн зондирующего излучения $\lambda_{1}=0.53$ и $\lambda_{2}=1.06 \mu \mathrm{m}$ и на состояние зон лазерного облучения, которое изучалось методами оптической и растровой электронной микроскопии. Наблюдаемое в эксперименте, связанное с импульсным нагревом плёнки, динамическое изменение $R-$ возрастание на $\lambda_{1}$ и уменьшение на $\lambda_{2}$, усиливается по мере повышения плотности энергии облучения $W$ с приближением к порогу лазерной абляции нитрида $\sim 1 \mathrm{~J} / \mathrm{cm}^{2}$. Лазерно-индуцированные теплофизические процессы, происходящие при $W=0.6-0.9 \mathrm{~J} / \mathrm{cm}^{2}$, приводят к специфической модификации слоя TiAlN с образованием сетки трещин из-за возникающих во время действия лазерного импульса термических напряжений. Повышение $W$ приводит к образованию более развитой сетчатой/ячеистой структуры плёнки, характеризующейся меньшим средним размером ячеек.
\end{abstract}

Ключевые слова: тонкие пленки, бинарный нитрид, лазерное облучение.

DOI: $10.21883 /$ OS.2020.01.48852.253-19

\section{Введение}

Бинарный нитрид TiAlN известен как материал защитных покрытий [1] и коррозионно- и износостойких упрочняющих слоёв, формируемых в технологии производства режущих инструментов [2,3]. Этот материал обладает также высокой радиационной стойкостью [4]. Исследование воздействия интенсивного импульсного лазерного излучения (ЛИ) на тонкие слои/плёнки TiAlN позволяет выяснить особенности трансформации состояния данного материала при высокотемпературном кратковременном нагреве и получить научную информацию о поведении его в экстремальных термодинамических условиях. В работах [5-10], связанных с импульсным лазерным облучением/отжигом (ИЛО) слоёв $\mathrm{TiN}$ и TiAlN с целью выяснения эффектов ИЛО, исследуемые материалы модифицировались в разнообразных режимах воздействия ЛИ, различающихся по длительности импульсов $\tau_{l p}$ (от фемто- до миллисекундных значений), длине волны $\lambda_{l p}$, плотности энергии $W$ в лазерном пятне и кратности облучения.

Отмечается [7], что в процессах модификации тонких плёнок наносекундными лазерными импульсами более выражены термические эффекты в сравнении с пико- и фемтосекундными режимами ИЛО. В наносекундных режимах ИЛО, в частности, исследовалось поведение композиционных покрытий из чередующихся тонких слоёв TiAlN/TiN [8] в условиях воздействия излучения $\mathrm{CO}_{2}$-лазера $\left(\lambda_{l p}=10.6 \mu \mathrm{m}, \tau_{l p}=100 \mathrm{~ns}\right)$ и покрытий из нитридных соединений TiAlN, TiCN и TiN [9]. В работе [9] проведено сравнительное исследование устойчивости/деградации указанных нитридов в связи с термоударом, инициируемым импульсным нагревом лазерным УФ излучением $\left(\lambda_{l p}=213 \mathrm{~nm}\right)$ длительностью менее $6 \mathrm{~ns}$, при превышении величиной $W$ порога абляции $W_{\mathrm{a}}$ тестируемого материала.

В данной работе изучались эффекты взаимодействия наносекундного излучения рубинового лазера $\left(\lambda_{l p}=694 \mathrm{~nm}\right)$ с тонкими плёнками TiAlN при $W \leq W_{\mathrm{a}}$, сформированными на кремниевых подложках методом магнетронного напыления. Исследование проводилось на основе применения новой совокупности методов эксперимента, включающей наряду с оптической и растровой электронной микроскопией (РЭМ) оптическую диагностику процессов ИЛО на двух длинах волн зондирующего излучения (ЗИ) путём детектирования потоков ЗИ, отражённого от модифицируемой области образцов TiAlN/Si. 


\section{Эксперимент}

В технологии приготовления образцов непосредственно перед напылением плёнок TiAIN производилась ионная $\left(\mathrm{Ar}^{+}\right)$очистка подложек $\mathrm{Si}(100)$ в течение $5 \mathrm{~min}$ при давлении аргона в источнике ионов $6.0 \cdot 10^{-2} \mathrm{~Pa}$, токе и напряжении разряда $20 \mathrm{~mA}$ и $2.4 \mathrm{kV}$ соответственно. Формирование плёнок разной толщины $d=0.2 \mu \mathrm{m}\left(d_{1}\right)$ и $0.5 \mu \mathrm{m}\left(d_{2}\right)$ проводили магнетронным распылением мозаичной мишени (содержащей в титановой основе цилиндрические вставки из алюминия) в аргон-азотной атмосфере при давлении газовой смеси $7.0 \cdot 10^{-2} \mathrm{~Pa}$, температуре подложки $220^{\circ} \mathrm{C}$, расстоянии мишеньподложка $\sim 8 \mathrm{~cm}$ и мощности разряда, задаваемой в диапазоне $400-600 \mathrm{~W}$; время напыления $10 \mathrm{~min}\left(d_{2}\right)$ и $3 \min 30 \mathrm{~s}\left(d_{1}\right)$.

Элементный состав получаемых слоёв $\mathrm{TiAlN} / \mathrm{Si}(100)$ (измерялось на подложках из спектрально чистого углерода), измеренный методом резерфордовского обратного рассеяния ионов $\mathrm{He}^{+}$с энергией $1.4 \mathrm{MeV}$, энергетическое разрешение детектора $15 \mathrm{keV}$ (установка AN-2500 HVEE), характеризуется атомарным содержанием титана -34.69 at.\%, алюминия - 31.61, азота - 33.69 и кислорода - 0.01 at.\%. Также проводилось напыление аналогичных плёнок на подложки из стекла для тестирования оптических свойств TiAIN в видимой и ближней ИК областях спектра на спектрофотометре S-100.

Исследование эффектов ИЛО приготовленных образцов TiAlN/Si проводилось в экспериментальных условиях $[11,12]$ с применением рубинового лазера, работавшего в режиме генерации одиночных импульсов излучения, длительность которых $\tau_{\mathrm{lp}}$ составляла около $70 \mathrm{~ns}$ по уровню 0.5 .

Согласно схеме экспериментальной установки [12] в центральную область зоны ИЛО (диаметр $4 \mathrm{~mm}$ ) направлялся сфокусированный в пятно $\sim 1 \mathrm{~mm}$ пучок ЗИ $p$-поляризации (угол падения $40^{\circ}$ ), содержащий аксиально совмещённые потоки излучения с $\lambda_{1}=0.53$ и $\lambda_{2}=1.06 \mu \mathrm{m}$. Отражённые от образца потоки ЗИ с той и другой длинами волн пространственно разделялись светоделительным элементом и воспринимались фотоэлектронными умножителями ЭЛУ-ФТС $\left(\lambda_{1}\right)$ и ЭЛУ-ФТК $\left(\lambda_{2}\right)$, сигналы с которых подавались на входы двухканального цифрового осциллографа В-424.

Плотность энергии облучения $W$ системы TiAlN/Si варьировалась ослабляющими нейтральными фильтрами в интервале $0.2-1.6 \mathrm{~J} / \mathrm{cm}^{2}$ при неравномерности распределения $W$, воспроизводимой от импульса к импульсу с отклонением около $\pm 5-10 \%$ от средней плотности энергии по пятну. Состояние областей ИЛО изучалось визуально и под микроскопом. Для исследования микроструктуры исходных и лазерно-модифицированных слоёв TiAlN/Si применялся растровый электронный микроскоп Hitachi S-4800.

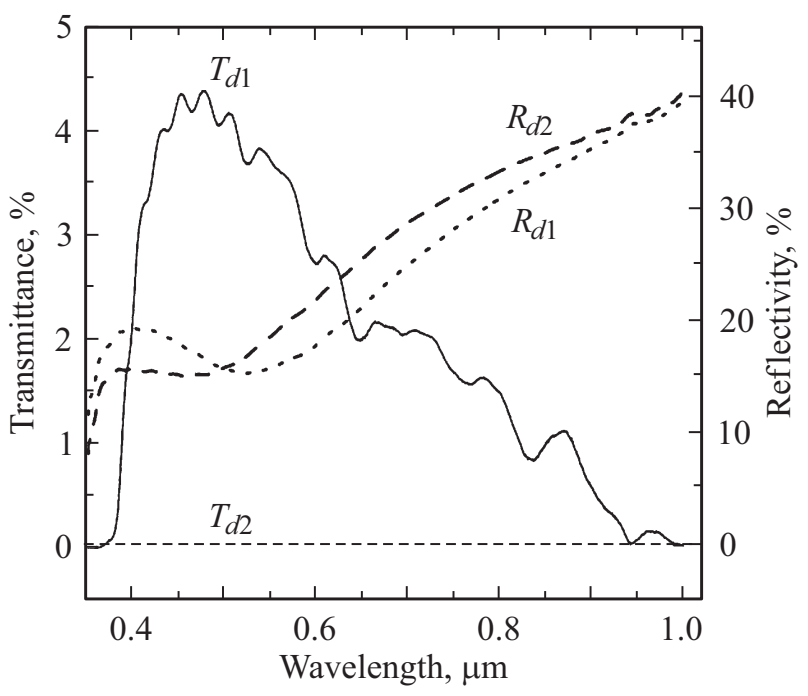

Рис. 1. Спектральные зависимости коэффициентов пропускания $\left(T_{d 1}, T_{d 2}\right)$ и отражения $\left(R_{d 1}, R_{d 2}\right)$ тонких плёнок TiAlN на стеклянных подложках.

\section{Результаты и обсуждение}

Согласно данным оптических измерений, выполненных на тестовых образцах TiAlN/стекло (покровное натриево-кальциевое стекло) в интервале длин волн 0.35-1.0 $\mu \mathrm{m}$ (рис. 1), максимальный по спектру коэффициент пропускания $T_{d 1}(\lambda)$ плёнки нитрида толщиной $d_{1}$ составляет немногим более $4 \%$ на $\lambda=0.45-0.48 \mu \mathrm{m}$. Плёнка большей толщины $\left(d_{2}=0.5 \mu \mathrm{m}\right)$ практически не пропускает излучение видимой и ближней инфракрасной областей спектра $\left(T_{d 2} \leq 10^{-4 \%}\right)$. Спектральные зависимости отражательной способности образцов с частично прозрачной $R_{d 1}(\lambda)$ и оптически плотной $R_{d 2}(\lambda)$ плёнками TiAlN не совпадают.

Зависимость $R_{d 2}(\lambda)$, в равной мере относящаяся к основному объекту исследования - системе TiAlN/Si $\left(d=d_{2}\right)$, определяется оптическими параметрами (комплексным показателем преломления в функции длины волны) собственно материала плёнки, характеризующегося величинами отражательной способности $28\left(\lambda_{l p}\right)$, $16\left(\lambda_{1}\right)$ и $40 \%\left(\lambda_{2}\right)$. Коэффициент пропускания $T_{d 1}(\lambda)$ на этих длинах волн равен 2.05, 3.74 и $0.032 \%$ соответственно. Используя эти данные, оценили десятичный показатель поглощения излучения в слое нитрида $\alpha(\lambda)$. Он составляет порядка $10^{5} \mathrm{~cm}^{-1}$ на $\lambda_{l p}$ и $\lambda_{1}$ и $\sim 2 \cdot 10^{5} \mathrm{~cm}^{-1}$ на $\lambda_{2}$. Из оценок величины $\alpha\left(\lambda=\lambda_{l p}\right)$ следует, что в условиях ИЛО плёнки TiAlN/Si $\left(d=d_{2}\right)$ глубина $\alpha^{-1}$ проникновения в неё лазерного излучения - глубина десятикратного ослабления интенсивности ЛИ примерно в 5 раз меньше величины $d_{2}$. Это означает, что рассматриваемые далее эффекты ИЛО фактически связаны с наносекундным воздействием поверхностного источника тепла, выделяющегося в образце при поглощении лазерного излучения. 

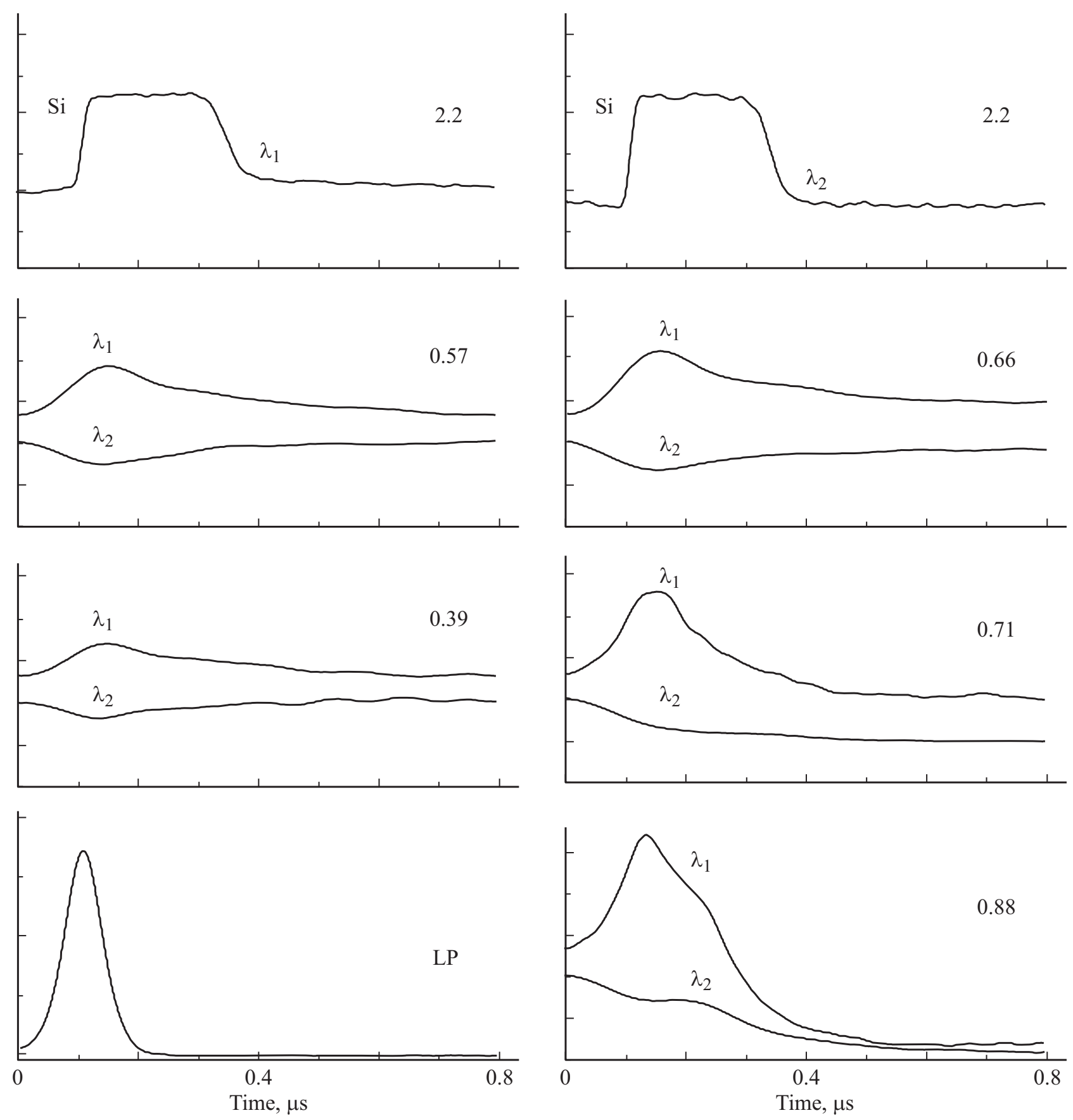

Рис. 2. Динамика отражательной способности плёнки TiAlN/Si толщиной $0.5 \mu \mathrm{m}$ и пластины кремния на длинах волн зондирующего пучка $0.53\left(\lambda_{1}\right)$ и $1.06 \mu \mathrm{m}\left(\lambda_{2}\right)$ в условиях воздействия моноимпульсного излучения (LP) рубинового лазера при ряде значений плотности энергии в лазерном пятне (указана над осциллограммами $\left[\mathrm{J} / \mathrm{cm}^{2}\right]$ ).

Воспользовавшись данными [13] о коэффициенте теплопроводности $(k=0.12 \mathrm{~W} / \mathrm{cm} \mathrm{K})$, удельной теплоёмкости $(C=0.48 \mathrm{~J} / \mathrm{g} \mathrm{K})$ и плотности TiAIN $\left(\rho=7.4 \mathrm{~g} / \mathrm{cm}^{3}\right)$, получаем оценочный (без учёта температурных зависимостей $k, C$ и $\rho$ ) коэффициент температуропроводности $\beta=(k / \rho C)=0.034 \mathrm{~cm}^{2} / \mathrm{c}$ этого материала и соответствующую глубину $d_{d}$ распространения (диффузии) тепла в образце за время импульсного поверхностного нагрева: $d_{d}=\left(\beta \tau_{\mathrm{lp}}\right)^{0.5} \approx 0.5 \mu \mathrm{m}$. То есть длина тепловой диффузии в системе TiAlN/Si на высокотемпературной стадии ИЛО приближается к толщине плёнки нитрида $d=d_{2}$. Это значит, что основная часть поглощаемой энергии ЛИ приводит к нагреву преимущественно плёнки с возникновением в ней высокого температурного градиента при значительно меньшем отводе тепла в подложку $\mathrm{Si}$.

$\mathrm{B}$ этой ситуации при плотностях энергии $W>0.2-0.3 \mathrm{~J} / \mathrm{cm}^{2}$ во время действия ЛИ наблюдается 

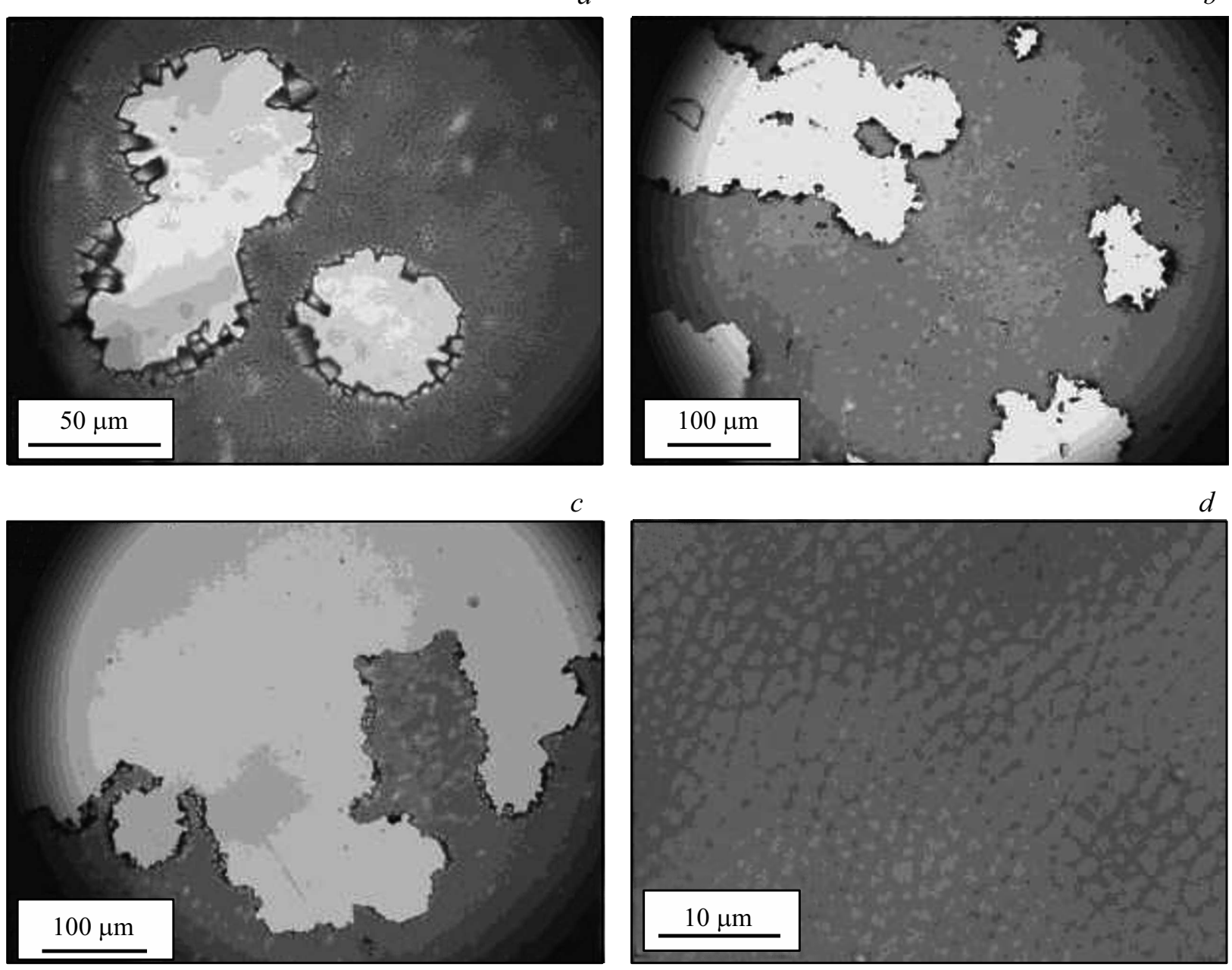

Рис. 3. Фрагменты изображения поверхности зон ИЛО в поле зрения микроскопа.

термостимулированное импульсным нагревом плёнки изменение её отражательной способности $R_{\lambda 1}(t)$ и $R_{\lambda 2}(t)$ на длинах волн ЗИ. Как следует из представленных осциллограмм (рис. 2), в сравнении с начальными коэффициентами отражения $\left(R_{i \lambda 1}\right.$ и $\left.R_{i \lambda 2}\right) R_{\lambda 1}(t)$ возрастает, a $R_{\lambda 2}(t)$ уменьшается соответственно до экстремальных значений $R_{\max \lambda 1}$ и $R_{\min \lambda 2}$. Наблюдаемый эффект усиливается по мере повышения $W$, т.е. достигаемой температуры поверхности образца. Так, соотношение $R_{\max \lambda 1} / R_{i \lambda 1}$, равное 1.22 при $W=0.39 \mathrm{~J} / \mathrm{cm}^{2}$, возрастает до $\quad 1.34 \quad\left(0.57 \mathrm{~J} / \mathrm{cm}^{2}\right) \rightarrow 1.45(0.66) \rightarrow 1.54(0.71) \quad$ и $1.76\left(0.88 \mathrm{~J} / \mathrm{cm}^{2}\right)$, причём максимум $R_{\lambda 1}(t)$ в процессе ИЛО достигается несколько позже момента пиковой мощности ЛИ - к моменту достижения наибольшей температуры поверхности плёнки. Изменение отношения $R_{\min \lambda 2} / R_{i \lambda 2}$ в динамике $R_{\lambda 2}(t)$ выражено слабее в той же последовательности задаваемых значений $W$ : $R_{\min \lambda 2} / R_{i \lambda 2}=0.85(0.39) \rightarrow 0.80(0.57) \rightarrow 0.74(0.66) \rightarrow$ $\left.\rightarrow 0.77(0.71) \rightarrow 0.78(0.88) \mathrm{J} / \mathrm{cm}^{2}\right)$.

При плотностях энергии 0.39 и $0.57 \mathrm{~J} / \mathrm{cm}^{2}$ непосредственно после окончания действия импульса ЛИ - на стадии диссипации тепловой энергии, введённой в плёнку, коэффициенты отражения $R_{\lambda 1}(t)$ и $R_{\lambda 2}(t)$ за время $t<1 \mu$ s восстанавливаются практически до исходных значений, т.е. в этих режимах облучения системы TiAlN/Si фиксируется обратимое изменение оптических характеристик нитридной плёнки, выраженное сильнее при более высокой величине $W$. Необратимое изменение в результате ИЛО наблюдается при дальнейшем повышении $W-$ с достижением модификации состояния/морфологии плёнки, более выраженной вследствие воздействия ЛИ с плотностью энергии $0.88 \mathrm{~J} / \mathrm{cm}^{2}$, приближающейся к энергетическому порогу абляции материала плёнки WaTiAlN $\sim 1 \mathrm{~J} / \mathrm{cm}^{2}$.

На рис. 2 приведены также осциллограммы, демонстрирующие поведение отражательной способности на той и другой длинах волн ЗИ механически и химически полированной пластины монокристаллического кремния (c-Si). Они характеризуют динамику отражения ЗИ в ситуации лазерно-индуцированного плавления приповерхностной области c-Si, которое достигается при превышении порогового значения $W=W_{\mathrm{mSi}} \sim 1 \mathrm{~J} / \mathrm{cm}^{2}$ [11], 

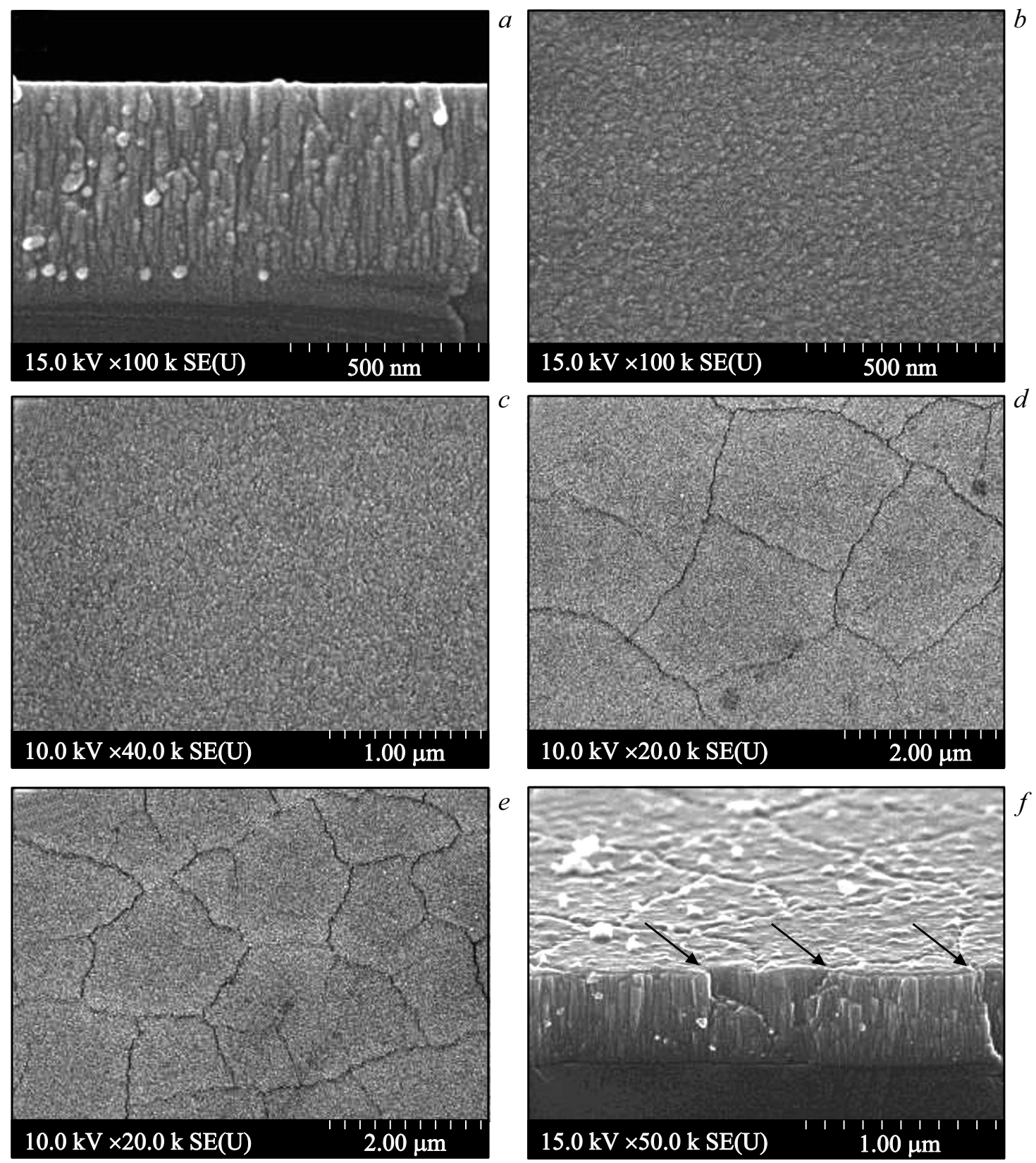

Рис. 4. РЭМ-снимки: скола образца TiAlN/Si $(a)$, поверхности исходной плёнки нитрида $(b)$, поверхности зон лазерного облучения при плотностях энергии $0.39(c), 0.46(d)$ и $0.57 \mathrm{~J} / \mathrm{cm}^{2}(e)$; снимок „f“ - картина скола при наклонной ориентации образца, облучённого при $W=0.9 \mathrm{~J} / \mathrm{cm}^{2}$, по отношению к сканирующему электронному пучку.

и по временной форме регистрируемых сигналов ФЭУ существенно отличаются от аналогичных осциллограмм, относящихся к ИЛО системы TiAlN/Si.

В ситуации с c-Si возникновение во время действия ЛИ сплошного наноразмерного слоя жидкой фазы (1-Si), обладающей физическими свойствами электронного расплава [14], приводит к скачкообразному возрастанию коэффициентов отражения $R_{\lambda 1}(t)$ и $R_{\lambda 2}(t)$ до квазистационарных максимумов, определяемых комплексными показателями преломления 1-Si [15] на длинах волн ЗИ, а также ориентацией поляризации и углом падения зон- дирующего пучка. Длительность состояния повышенной отражательной способности зоны ИЛО коррелирует с продолжительностью инициируемых фазовых переходов $\mathrm{c}-\mathrm{Si} \rightarrow 1-\mathrm{Si} \rightarrow \mathrm{c}-\mathrm{Si}$, т. е. с временем существования расплава $\tau_{\mathrm{m}}(W)$, которое в данном режиме облучения $\left(2.2 \mathrm{~J} / \mathrm{cm}^{2}\right)$ составляет $240 \mathrm{~ns}$, чему соответствует расчётная глубина проплавления монокристалла $\mathrm{Si} \sim 0.5 \mu \mathrm{m}[16]$.

В сравнении с ситуацией лазерно-индуцированного плавления кремния характер изменения отражательной способности плёнки TiAlN/Si при плотностях энергии ИЛО ниже $1 \mathrm{~J} / \mathrm{cm}^{2}$ (рис. 2) свидетельствует скорее о 
стабильности твёрдофазного состояния нитрида во время действия ЛИ. Наблюдаемая динамика отражения ЗИ от плёнки в процессе ИЛО наиболее вероятно обусловлена термостимулированным изменением её оптических параметров - комплексного показателя преломления бинарного нитрида на длинах волн ЗИ, при неизменном агрегатном состоянии.

Эффект усиливается по мере повышения $W$ и соответствующего увеличения степени импульсного нагрева, не превышающей, однако, температурный предел термодинамической стабильности твёрдого состояния нитрида. Достижение/преодоление этого предела $\left(W \geq 1 \mathrm{~J} / \mathrm{cm}^{2}\right)$ приводит к абляции TiAlN, происходящей, как представляется, вследствие термофотостимулированной диссоциации соединения с образованием низкотемпературной плазмы, что в результате приводит к частичному (рис. 3,a-c) или полному (при дальнейшем повышении $W$ ) удалению плёнки с подложки. На фотографиях „a $a^{6}$ и „ $b^{\text {с }}$ показаны области зон ИЛО с локальным отсутствием плёнки и отслоением её от подложки по краям этих областей $(a)$. Фотография „сс демонстрирует фрагмент периферии зоны ИЛО - переход от исходной плёнки в область её полного удаления/абляции, не приводящей, однако, к разрушению поверхности подложки.

Состояние участков поверхности образца, облучённых при энергиях $0.2-0.4 \mathrm{~J} / \mathrm{cm}^{2}$, визуально практически не отличалось от исходного, и зоны ИЛО не выделялись на пластине TiAlN/Si. При последовательном увеличении $W$ в интервале $0.4-0.9 \mathrm{~J} / \mathrm{cm}^{2}$ и однократном облучении новых участков эффект ИЛО становится всё более заметным - появляется слабый оптический контраст зон лазерного воздействия на общем фоне поверхности образца вследствие модификации состояния плёнки, о чём свидетельствует появление ячеистой/сетчатой структуры (рис. $3, d$ ). Средний размер ячеек, равный $\sim 2 \mu \mathrm{m}$ при ИЛО плёнки с плотностью энергии $0.46 \mathrm{~J} / \mathrm{cm}^{2}$, последовательно уменьшается примерно в два раза по мере увеличения $W$ с приближением к порогу абляции, которому соответствует расчётная температура поверхности плёнки около $2800 \mathrm{~K}\left(W=1 \mathrm{~J} / \mathrm{cm}^{2}\right)$ [17].

РЭМ-изображение исходной плёнки на сколе образца TiAlN/Si (рис. 4,a), полученное в режиме детектирования вторичных электронов, свидетельствует о её столбчатом строении, обусловленном спецификой кинетики формирования слоя бинарного нитрида указанным выше методом. Средний поперечный диаметр столбцов в процессе наращивания нитрида увеличивается от 23-25 до 47-50 nm, что приводит к соответствующей наноразмерной неоднородности поверхности плёнки (РЭМ-сни-

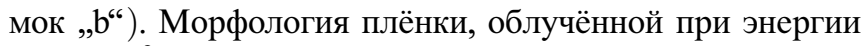
$0.39 \mathrm{~J} / \mathrm{cm}^{2}$ (рис. 4,c), практически не отличается от исходной. Показанная на РЭМ-снимках „, $d^{4}$ и „, $e^{\text {“ }}$ и отмеченная выше (рис. $3, d$ ) ячеистая морфология лазерномодифицированной плёнки есть следствие образования сетки трещин в процессе релаксации термических напряжений, вызванных весьма значительным перепадом температуры по толщине слоя TiAlN - градиентом температуры порядка $10^{7} \mathrm{~K} / \mathrm{cm}$, возникающим в процессе ИЛО. На приведённом снимке стрелками указаны фрагменты трещин, попавшие в плоскость скола плёнки.

Образование сетки трещин усиливается с повышением $W$ и достижением тем самым большей максимальной температуры поверхности плёнки и более высокого температурного градиента. Это приводит, как отмечалось выше, к уменьшению среднего размера ячеек, т.е. к более развитой ячеистой структуре модифицированной плёнки. Следует отметить, что аналогичные особенности лазерной модификации нитридных плёнок установлены, в частности, при РЭМ-исследовании воздействия пикосекундных импульсов излучения второй гармоники $\mathrm{Nd}$ :YAG-лазера на плёнки $\mathrm{TiN} / \mathrm{Si}(111)$ толщиной $2.6 \mu \mathrm{m}$ [7]. Формирование сетки трещин с субмикронными ячейками наблюдалось в сравнении с нашей экспериментальной ситуацией при более высокой $\left(5.9 \mathrm{~J} / \mathrm{cm}^{2}\right)$ плотности энергии в лазерном импульсе длительностью $40 \mathrm{ps}\left(\lambda_{l p}=532 \mathrm{~nm}\right)$. Образование трещин интерпретируется в [7] различием теплофизических параметров $\mathrm{TiN}$ и кремния и их изменениями при весьма быстром лазерном нагреве и последующем высокоскоростном охлаждении.

\section{Заключение}

В результате проведённого исследования установлено, что в определённом интервале плотностей энергии наносекундного лазерного облучения тонкоплёночной системы TiAlN/Si ниже порога разрушения/абляции субмикронной нитридной плёнки лазерно-индуцированные теплофизические процессы приводят к разной по знаку изменения динамике её отражательной способности на длинах волн видимой $\left(\lambda_{1}\right)$ и ближней инфракрасной $\left(\lambda_{2}\right)$ областей спектра. Изменение коэффициентов отражения - возрастание на $\lambda_{1}$ и уменьшение на $\lambda_{2}$, связанное с температурной зависимостью комплексного показателя преломления материала плёнки, усиливается по мере повышения энергии лазерного облучения и соответственно температуры поверхности образца.

Стимулированные лазерным воздействием теплофизические процессы, происходящие в плёнке TiAlN при неизменном (твёрдофазном) агрегатном состоянии нитрида, приводят к специфической модификации плёнки ячеистой/сетчатой морфологии из-за образования системы трещин на стадии релаксации термических напряжений, возникающих во время действия лазерного импульса. Повышение плотности энергии лазерного облучения тонкоплёночной системы способствует формированию более развитой ячеистой структуры плёнки с меньшим средним размером ячеек.

В условиях лазерно-идуцированного разрушения/абляции нитридной плёнки основная часть поглощаемой энергии лазерного излучения в общем энергетическом балансе инициируемых теплофизических процессов в 
рассматриваемой гетеросистеме обусловливает высокотемпературный нагрев плёнки, изменение её агрегатного состояния и удаление TiAIN с подложки кремния.

\section{Финансирование работы}

Работа выполнена при финансовой поддержке Министерства образования РБ по заданию 2.18.1 Государственной научно-технической программы „Физическое материаловедение, новые материалы и технологии“.

\section{Конфликт интересов}

Авторы заявляют, что у них нет конфликта интересов.

\section{Список литературы}

[1] Погребняк А.Д., Дробышевская А.А., Береснев В.М и др. // ЖТФ. 2011. Т. 81. C. 124-131.

[2] Leyendecker T., Lemmer O., Esser S., Ebberink J. // Surface and Coatings Technology. 1991. V. 48. P. 175.

[3] Vetter J. // Surface and Coatings Technology. 1995. V. 719. P. 76-77.

[4] Комаров Ф.Ф., Константинов С.В., Стрельницкий В.Е., Пилько В.В. // ЖТФ. 2016. Т. 86. В. 5. С. 57-63.

[5] Yasumaru N., Miyazaki K., Kiuchi J. // Appl. Phys. A. 2003. V. 76. P. $983-985$.

[6] Yasumaru N., Miyazaki K., Kiuchi J. // Appl. Phys. A. 2005. V. 81. P. 933-937.

[7] Gakovic B., Trtica M., Batani D. et al. // J. Opt. A. 2007. V. 9. P. S76-S80.

[8] Gakovic B., Trtica M., Radak B. et al. // J. Opt. A. 2009. V. 11. P. 1-6.

[9] Seol Jeon, Heesoo Lee // J. Korean Ceramic Soc. 2013. V. 50. P. 523-527.

[10] Deng J., Li S., Xing Y., Li Y. // Surface Engineering. 2014. V. 30. P. 195-203.

[11] Ивлев Г.Д., Гацкевич Е.И. // ЖТФ. 2012. Т. 82. С. 69-72.

[12] Новиков Г.А., Баталов Р.И., Баязитов Р.М., Файзрахманов И.А., Ивлев Г.Д., Прокопьев С.Л. // ЖТФ. 2015. Т. 85. C. 89-95.

[13] Михайлов А.Н., Сидорова Е.В., Волохов Д.В. // Прогресивні технологіi і системи машино-будування: міжнар. зб. наук. 2011. В. 41. С. 225-233.

[14] Регель А.Р., Глазов В.М. Физические свойства электронных расплавов. М.: Наука, 1980. 296 с.

[15] Ивлев Г.Д., Гачкевич Е.И. // ФТП. 1996. Т. 30. C. 2097-2107.

[16] Пилипович В.А., Малевич В.Л., Ивлев Г.Д., Жидков В.В. // ИФЖ. 1985. Т. 48. С. 306-312.

[17] Гачкевич Е.И., Ивлев Г.Д., Людчик О.Р. // Труды XXVI межд. конф. „Радиационная физика твёрдого тела“. М.: ФГБНУ „НИИ ПМТ“, 2016. С. 1160122. 